\title{
Laurent Drelincourt, Sonnets Chrétiens sur divers sujets
}

Benedetta Papasogli

\section{(2) OpenEdition}

\section{Journals}

\section{Edizione digitale}

URL: http://journals.openedition.org/studifrancesi/36067

DOI: 10.4000/studifrancesi.36067

ISSN: 2421-5856

\section{Editore}

Rosenberg \& Sellier

\section{Edizione cartacea}

Data di pubblicazione: 1 juillet 2005

Paginazione: 157

ISSN: 0039-2944

\section{Notizia bibliografica digitale}

Benedetta Papasogli, «Laurent Drelincourt, Sonnets Chrétiens sur divers sujets», Studi Francesi [Online], 145 (XLIX | I) | 2005, online dal 30 novembre 2015, consultato il 18 avril 2021. URL: http:// journals.openedition.org/studifrancesi/36067 ; DOI: https://doi.org/10.4000/studifrancesi.36067

Questo documento è stato generato automaticamente il 18 avril 2021.

\section{(c) $(7)$}

Studi Francesi è distribuita con Licenza Creative Commons Attribuzione - Non commerciale - Non opere derivate 4.0 Internazionale. 


\title{
Laurent Drelincourt, Sonnets Chrétiens sur divers sujets
}

\author{
Benedetta Papasogli
}

\section{NOTIZIA}

LAURENT DRELINCOURT, Sonnets Chrétiens sur divers sujets, texte établi, présenté et annoté par Julien GOEURY, Paris, Honoré Champion («Sources classiques»), 2004, pp. 450.

1 Apparsi alla vigilia della revoca dell'editto di Nantes, i Sonnets chrétiens di Drelincourt (1677) sono un brillante e raro esempio di poesia protestante tardiva, e al tempo stesso una delle ultime belle raccolte in versi del secolo che conosceva il tramonto della lirica. Consultando la bibliografia della presente edizione si tocca con mano una situazione critica, non insolita per i minori del Seicento, e tuttavia paradossale. Quasi non esistono studi su Laurent Drelincourt: si riducono a pochissimi interventi, apparsi in questi ultimi anni, di François-Xavier Cuche e dello stesso Julien Goeury curatore dell'edizione che presentiamo; ma un'ampia messe di studi sul Seicento è chiamata in causa, dalla storia alla letteratura, dalla devozione all'eloquenza, dal barocco al classicismo, come a testimoniare ancora una volta che sui minori un fascio di linee culturali convergono, le più caratteristiche di un'epoca.

2 Per di più, se nella stessa bibliografia si paragona la scheda delle opere di Laurent Drelincourt a quella del padre Charles Drelincourt, si costata quanto il figlio dovette vivere all'ombra del padre, più longevo di lui, che scrisse a lui e per lui un'epistola dai toni di panegirico. E infatti la vita del poeta morto a cinquantacinque anni svolgendo il suo ministero di pastore a Niort sembra aver lasciato nei contemporanei e nei correligionari il segno edificante di una "faiblesse rayonnante". Non che sia stata una vita di pura austerità e rinuncia: predicatore di successo, Laurent Drelincourt fu coinvolto, specie nel periodo trascorso a Parigi, in una socievolezza mondana che testimonia di interscambi fra il tempio ed il salotto, e di una presenza protestante assai vicina alle cerchie della società preziosa e influente (come ha mostrato Roger Zuber) 
nella formazione del gusto classico. In particolare l'incontro con Conrart dovette essere determinante per l'orientamento letterario di Drelincourt. Si deve anche alla sua pratica di una onesta socievolezza se Drelincourt poeta cristiano, scrive Goeury, "se place d'emblée du côté de l'agrément et non de la contrainte, du côté de la douceur et non de la force." (p. 86).

3 La raccolta dei Sonnets Chrétiens obbedisce, persino nei numeri, a rigorose leggi di costruzione. Vi è in essa una "geometria" (F. X. Cuche) tutta classica che si sposa al gusto, che qualcuno definirà barocco, dell'antitesi e dell'ambivalenza. L'esito più costante è quello di un dinamismo ordinato, di un'effervescenza conclusa da forme di "paralogie conceptueuse" (p. 72) con bilanciamento o rovesciamento di valori nella "pointe" finale, nel paradosso prevedibile. L'interessante Avertissement del poeta annuncia all'interno della raccolta un dosaggio libero e vario di "agrément" e di "utilité", una mescolanza di "fiori" (immaginativi e delicati) e di "frutti" (semplici e naturali), una fluttuazione tra i poli della poesia e della prosa. Nonostante la geometria dell'insieme, l'estetica delle forme brevi e discontinue si affaccia originalmente già sulla soglia della raccolta, sotto la metafora della musica leggera ("petits airs séparez") e della passeggiata interrotta.

4 È a questo aspetto, e ai giochi ritmici, metrici e retorici, che dedica particolare attenzione Julien Goeury, dopo uno sviluppo biografico in cui è tratteggiata la personalità di Drelincourt sullo sfondo dei cenacoli protestanti del tempo. Drelincourt poeta biblico, teologo dall'inclinazione ecumenica, ricco di dottrina e di cultura che si manifestano ora nello scorso di un'esegesi tipologica, ora nell'adattamento di un modello umanistico ed eroico, susciterà, speriamo, analisi nuove e approfondite. Ma già da questo studio introduttivo emergono pienamente le coordinate della sua posizione storica e letteraria. Editore dei sermoni di Drelincourt, studioso di Jean de La Ceppède, specialista di poesia dell'età classica, Goeury ha tutti gli strumenti per valorizzare consonanze e corrispondenze, senza privare Drelincourt della sua mandorla suggestiva: una certa solitudine. 